\title{
Multiple drug hypersensitivity associated with severe cutaneous adverse reaction
}

\author{
Karen Jui Lin Choo ${ }^{*}$, Shiu Ming Pang ${ }^{2}$, Haur Yueh Lee \\ From 6th Drug Hypersensitivity Meeting (DHM 6) \\ Bern, Switzerland. 9-12 April 2014
}

\section{Background}

Multiple Drug Hypersensitivity (MDH) was first described by Sullivan et al in 1989 as drug allergies to two or more chemically different drugs proven by in-vivo or in-vitro testing. Pichler et al added to this description by suggesting that there are two subtypes of MDH: one where sensitisation to different drug classes may occur simultaneously; the other, sequentially - sometimes even years apart.

\section{Methods}

We describe three patients matching the description of $\mathrm{MDH}$.

\section{Results}

We described three patients, aged 47, 68 and 75 with a history of severe cutaneous adverse reaction (SCAR) to non-antibiotic medication (two of the cases were to allopurinol and the other was to omeprazole). All three later developed an exanthem ( 4 to 37 months later) to penicillin-based antibiotics that they were exposed to during the period of 5 to 20 days of their initial SCAR. 1 patient had a positive patch test to the antibiotic.

\section{Conclusion}

Our findings support the hypothesis that concomitant sensitisation to medication(s) given at or around the time of a previous severe cutaneous drug reaction results in multiple drug hypersensitivity syndrome. New or unnecessary medication should be avoided in the initial period following SCAR.

\footnotetext{
Authors' details

'Singapore General Hospital, Dermatology Unit and Allergy Clinic, Singapore. ${ }^{2}$ Singapore General Hospital, Dermatology Unit, Singapore.
}

'Singapore General Hospital, Dermatology Unit and Allergy Clinic, Singapore Full list of author information is available at the end of the article
Published: 18 July 2014

doi:10.1186/2045-7022-4-S3-P135

Cite this article as: Lin Choo et al:: Multiple drug hypersensitivity associated with severe cutaneous adverse reaction. Clinical and Translational Allergy 2014 4(Suppl 3):P135.
Submit your next manuscript to BioMed Central and take full advantage of:

- Convenient online submission

- Thorough peer review

- No space constraints or color figure charges

- Immediate publication on acceptance

- Inclusion in PubMed, CAS, Scopus and Google Scholar

- Research which is freely available for redistribution
() Biomed Central

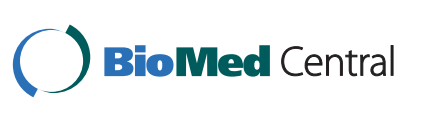

